\title{
INSM1 Expression in Breast Neoplasms with Neuroedocrine Features
}

\author{
Jasna Metovic ${ }^{1} \cdot$ Isabella Castellano $^{2}$ (1) Eleonora Marinelli ${ }^{1} \cdot$ Simona Osella-Abate $^{2} \cdot$ Anna Sapino $^{2,3}$. \\ Paola Cassoni ${ }^{2} \cdot$ Mauro Papotti $^{1}$
}

Accepted: 11 May 2021 / Published online: 19 May 2021

(c) The Author(s) 2021

\begin{abstract}
According to the 2019 WHO classification of breast tumors, neuroendocrine neoplasms (NENs) are classified into welldifferentiated NE tumors (NET) and poorly differentiated NE carcinomas (NEC), while other breast cancers (BCs) of special and no special type with neuroendocrine (NE) features are not incorporated in this scheme anymore. We aimed to assess whether INSM1, a novel NE marker, could have a role in breast NEN subtyping. We selected 63 BCs operated from 2003 to 2018, classified as BCs with NE features, with available clinico-pathological data. Following 2019 WHO criteria, this cohort was reclassified into $37 \mathrm{NETs} / \mathrm{NECs}$, the remaining 26 tumors representing solid-papillary (7), mucinous (7), and mixed type (12) carcinomas with NE differentiation. Chromogranin A (CGA) and synaptophysin (SYN) immunostains were reviewed, and INSM1 was tested by immunohistochemistry. Thirty CGA- and SYN-negative no special type BCs served as negative control. INSM1 was expressed in 52/63 cases of the whole cohort (82.54\%). INSM1 positive and negative cases had no significantly different clinico-pathological characteristics. INSM1 expression was not significantly different between the newly reclassified NET/NEC group and other BCs with NE features. No immunoexpression was observed in control BCs. The sensitivity and specificity of INSM1 for the NE phenotype was $82.5 \%$ and $100 \%$, respectively, compared to $61.9 \%$ and $100 \%$ for CGA, and 95.2 and 100\% for SYN. In conclusion, INSM1 is as accurate as traditional NE biomarkers to identify NE differentiation in BC. In analogy to standard NE markers, INSM1 could not distinguish NET and NEC from the other $\mathrm{BC}$ histotypes with NE differentiation.
\end{abstract}

Keyword INSM1 $\cdot$ Neuroendocrine differentiation $\cdot$ Breast carcinoma $\cdot$ Histotype

\section{Introduction}

The definition of neuroendocrine neoplasms (NEN) of the breast is hampered by continuous efforts to identify precise diagnostic criteria, as reflected by the different classification systems proposed by the WHO schemes in 2003 [1], 2012 [2], and 2019 [3].

In particular, the last WHO edition [3] proposes to classify NEN of the breast into NE tumors (NET) and NE carcinomas (NEC), in analogy to NEN originating from the gastroenteropancreatic tract and lung [4].

Isabella Castellano

isabella.castellano@unito.it

1 Department of Oncology, Pathology Unit, University of Turin, Via Santena 7, 10126 Turin, Italy

2 Department of Medical Sciences, Pathology Unit, University of Turin, Via Santena 7, 10126 Turin, Italy

3 Pathology Division, Candiolo Cancer Institute, FPO-IRCCS, 10060 Candiolo, Italy
NET and NEC in the breast, as defined by the latest WHO classification, are characterized by well-differentiated and poorly differentiated neuroendocrine morphology, respectively, and they both show ultrastructural and immunohistochemical (IHC) features of neuroendocrine differentiation, supported by the presence of neurosecretory granules and a diffuse immunoreactivity for NE markers. Specifically, NETs are well or intermediate differentiated tumors, while NECs are poorly differentiated BC. BCs with NE features, such as solid papillary carcinoma, pure mucinous carcinoma (representing special $\mathrm{BC}$ histotypes), and tumors with mixed histology, have been excluded from the current WHO classification of breast NEN [3].

A novel marker called insulinoma-associated protein 1 (INSM1) has been identified in insulinoma tissue [5] and subsequently detected in different NE human cells and tumors. INSM1 is a zinc-finger transcription factor that through interactions with ASH1 and BRN2 [6, 7] favors the expression of well-established NE markers chromogranin A 
(CGA), synaptophysin (SYN), and CD56 [8, 9], representing key regulators of NE differentiation $[6,10,11]$. In healthy tissues, the nuclear expression of INSM1 is limited to NE cells of pancreatic islets, adrenal medulla, gastro-intestinal, and bronchopulmonary tract [12-14]. Moreover, INSM1 is strongly expressed in most NE tumors, with a specific nuclear staining [15]. However, to the best of our knowledge, only few $\mathrm{BC}$ with NE features were investigated for INSM1 expression [16-18].

Considering this background, aims of this study are (i) to test INSM1 specificity and sensitivity for the NE phenotype in $\mathrm{BC}$ and (ii) to assess whether INSM1 expression may differentiate the novel NET/NEC categories from the other $\mathrm{BC}$ with NE features.

\section{Material and Methods}

\section{Case Selection}

From the pathology files of the Città della Salute e della Scienza University Hospital in Turin, key words such as "breast," "carcinoma," "neoplasm," "infiltrative," and "neuroendocrine" were searched to select a series of $63 \mathrm{BC}$ with NE features, operated from 2003 to 2018, with sufficient residual material for IHC investigations. A series of 30 invasive BC of no special type (NST) with no expression of CGA and SYN served as the control group.
For each case, clinical-pathological data such as age, site of lesion, type of surgery, type of therapy, and follow up data were obtained from clinical charts. In addition, information regarding tumor size, lymph nodal status, histological grade, vascular invasion, estrogen (ER), progesterone (PgR), human epidermal growth factor receptor 2 (HER2) receptor status, and Ki67 proliferation index were retrieved from pathological reports. Both ER and PgR were considered as positive if more than $1 \%$ of tumor cells had a nuclear immunostaining [19]. HER2 status was classified as negative (score $0,1+$, and $2+$ not amplified) or positive (when scored $3+$ by IHC or HER 2 amplified by FISH) according to the recommended guidelines for invasive carcinoma [20]. CGA and SYN expressions were recorded, as well.

Surrogate molecular profile was obtained according to the recommendations of St. Gallen 2013 [21].

Each case was reviewed by the three of us (JM, IC, MP) and reclassified strictly following the criteria of the last 2019 WHO edition [3]. Specifically, NET diagnosis was referred to neoplasms with typical solid nests or trabeculae of spindle/polygonal/plasmacytoid cells, separated by fibrovascular stroma (Fig. 1a/b). The diagnosis of NEC was restricted to high-grade tumors, morphologically resembling pulmonary high-grade NE carcinomas. NEC were composed either of small cells with extensive necrosis, uniform small dark hyperchromatic cells with high nuclear/cytoplasm ratio, or large cells with evident cytoplasm and highly pleomorphic nuclei (Fig. 1c/d). At least one extensive positivity of
Fig. 1 A case of neuroendocrine breast tumor $(\mathbf{a} / \mathbf{b}, 100 \times / 200 \times)$ showing typical solid nest growth separated by fibrovascular stroma. A case of neuroendocrine breast carcinoma (c/d, $200 \times / 400 \times$ ) displaying high number of mitotic figures, pleomorphic nuclei, and foci of necrosis
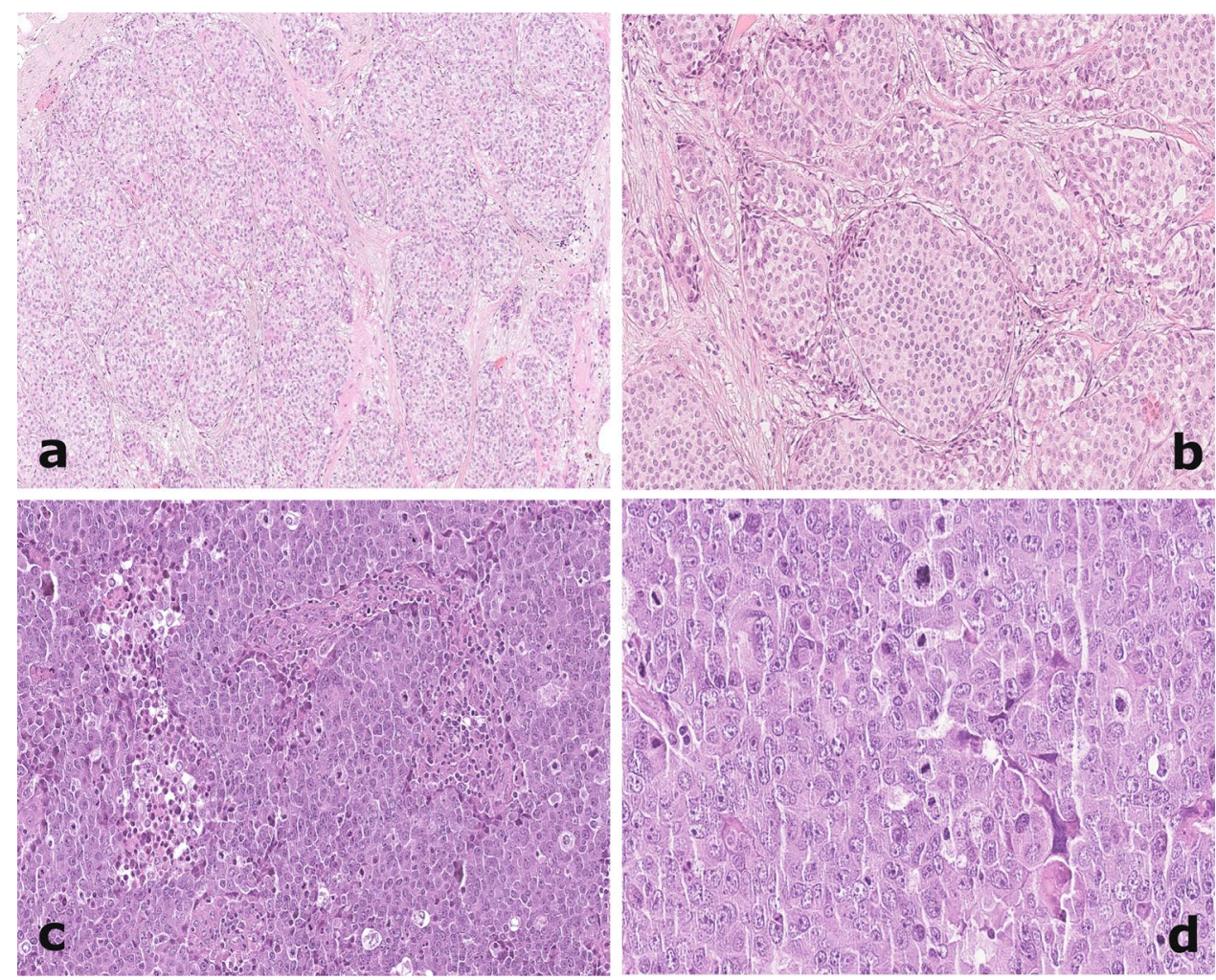
traditional NE marker (CGA and/or SYN) was required to confirm the morphological diagnosis.

The study was approved by the Research Ethics Committee for Human Biospecimen Utilization (Department of Medical Sciences-ChBU) of the University of Turin (no. $5 / 2020$ ). Written consent was not required considering the retrospective nature of the study. The study was conducted in accordance with The Code of Ethics of the World Medical Association (Declaration of Helsinki). All cases were deidentified, and all clinical-pathological data were accessed anonymously.

\section{Immunohistochemistry}

All cases were stained for INSM1 (clone A8, Santa Cruz Biotechnology, Santa Cruz, CA, diluted 1:100) using an automated immunostainer platform (BenchMark AutoStainer, Ventana Medical Systems, Tucson, AZ, USA). The intensity (weak to strong) and the percentage of positive tumor cell nuclei were recorded. The cut off for a positive reaction was set at $5 \%$ of tumor cells, as previously reported [22]. Pancreatic tissue, representing appropriate positive (Langerhans islets) and negative (acinar cells) controls, was included in each IHC run.

When missing from the file, CGA (clone LK2H10, Ventana, prediluted) or SYN (clone SP11, Ventana, prediluted) were tested using the BenchMark AutoStainer. Both markers were classified as (i) diffusely positive if present in more than $50 \%$ of tumor cells, (ii) focally positive if present in $<50 \%$ of tumor cells, and (iii) absent if no staining was observed.

\section{Statistical Analysis}

Statistical analyses were carried out using Stata 15.0 software (StataCorp, College Station, TX, USA). The differences in the distribution of the variables evaluated based on clinical-pathological parameters were analyzed using parametric and non-parametric tests (Student's $t$ test, Pearson's chi-square test and Bonferroni's correction, Wilcoxon's rank test).

Sensitivity, specificity, positive predictive value (PPV), and negative predictive value (NPV) were calculated, as previously described [23].

Time to relapse (relapse-free interval-RFI) was assessed from the date of diagnosis to the date of relapse or the date of the last checkup. Overall survival (OS) was assessed from the date of diagnosis to the date of death from any cause or to the date of the last checkup. All dead patients were considered as events.

Survival analysis was determined by the Kaplan-Meier curves, and Mantel log-rank test was used to compare statistical differences.

\section{Results}

Upon revision, 37 cases were recorded as NENs, namely, 9 NET G1, 20 NET G2, and 8 NEC, the latter group consisting of 6 large-cell and 2 small-cell neuroendocrine carcinomas. The remaining 26 tumors despite more or less extensive expression on NE markers did not meet the morphological criteria recommended by 2019 WHO scheme and were referred as "BC with NE differentiation." This group included solid papillary (7 cases), mucinous (7 cases), and mixed type (12 cases) carcinomas (having a NE morphology in $<10 \%$ of the tumor area).

\section{NE Marker Expression in the Whole Series}

INSM1 was expressed in 52/63 (82.5\%) of the whole cohort (Fig. 2a-d). INSM1 negative and positive cases did not demonstrate statistically significant differences in clinicopathological characteristics, nor regarding the surrogate molecular profile status, as shown in Table 1. SYN and CGA were positive in 60/63 (95.2\%) and 39/63 (61.9\%) cases, respectively (Table 1; Fig. 2e/f).

INSM1 and SYN expression was discordant in 14/63 cases (22\%) (11 INSM1 negative and SYN positive and 3 INSM1 positive and SYN negative) (Fig. 3a). INSM1 and CGA expression was discordant in 25/63 (39.7\%) tumors (6 INSM1 negative and CGA positive and 19 INSM1 positive and CGA negative), indicating that INSM1 identifies few SYN-negative cases and a relevant fraction of CGA-negative tumors (Fig. 3b). INSM1 expression was not detected in any of the 30 NST control BC. Clinico-pathological characteristics of these cases are reported in Supplementary Table 1. Hence, INSM1 showed $82.54 \%$ (70.90-90.95, 95\% CI) sensitivity and $100 \%(88.43 \%-100.0 \%, 95 \% \mathrm{CI})$, specificity, with PPV 100\% and NPP 73.17\% (61.45-82.35\%, 95\% CI). In this series, CGA sensitivity was $61.90 \%$ (48.8-73.85, 95\% CI), specificity $100 \%(88.43-100 \%, 95 \%$ CI), PPV $100 \%$, and NPV 55.5\% (47.71-63.13, 95\% CI); SYN sensitivity was $95.24 \%(86.71-99.01,95 \% \mathrm{CI})$, specificity $100 \%$ (88.43-100\%, 95\% CI), PPV 100\%, and NPV $90.91 \%$ (76.82-96.79, 95\% CI).

\section{Comparison of NE Marker Expression in NET/NEC and BC with NE Differentiation, According to 2019 WHO Classification}

No significant differences were observed among the new NET/NEC categories (37 cases) and BC with NE differentiation cancers ( 26 cases) regarding clinico-pathological features and CGA expression (Table 2). Conversely, SYN immunoreactivity was preferentially observed in NENs $(100 \%)$ compared with $\mathrm{BC}$ with $\mathrm{NE}$ differentiation $(88.5 \%, P=0.034)$. 


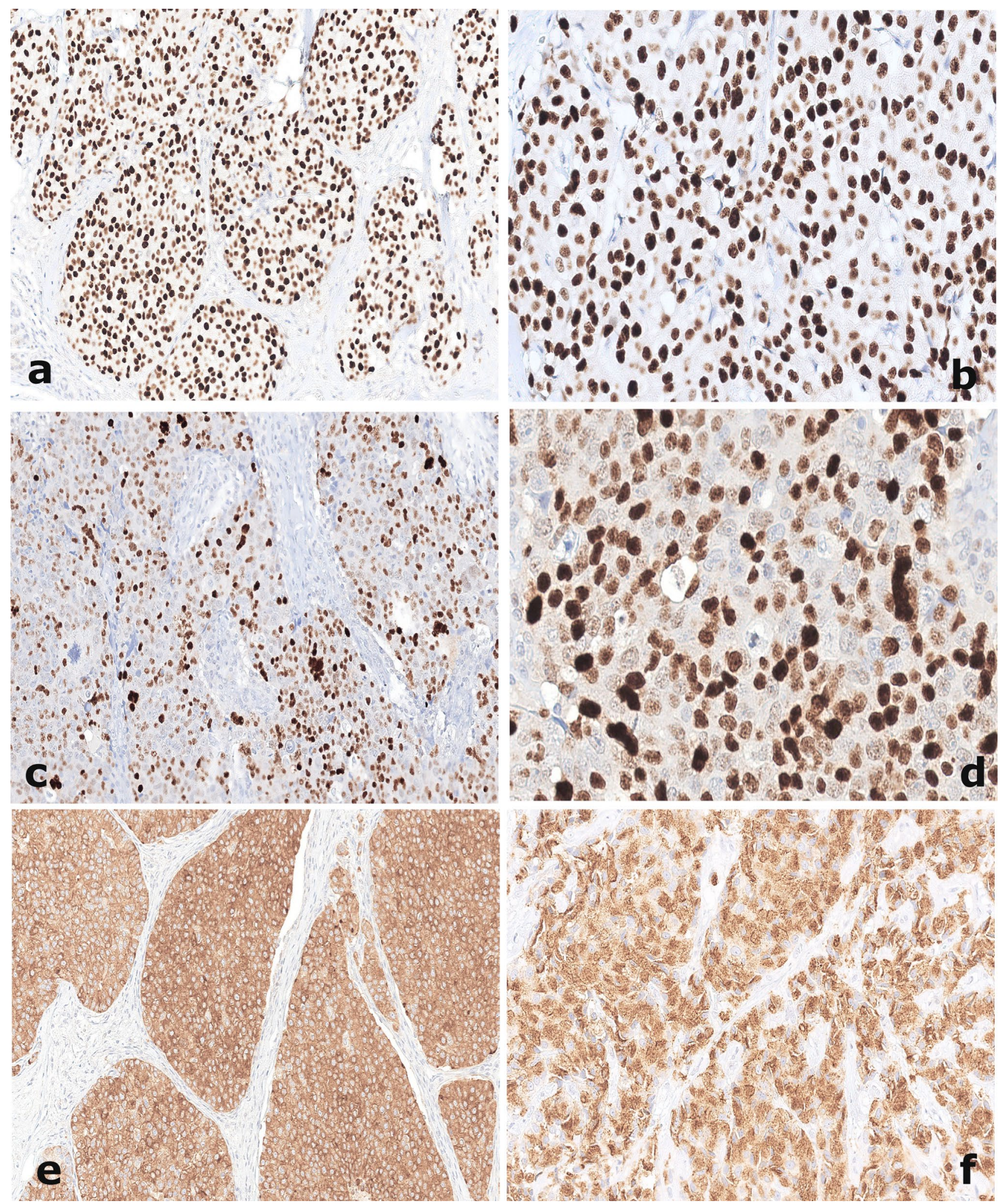

Fig. 2 Strong and diffuse nuclear INSM1 immunoreactivity in a case of neuroendocrine breast tumor $(\mathbf{a} / \mathbf{b}, 200 \times / 400 \times)$ and in a case of neuroendocrine breast carcinoma (c/d, $200 \times / 400 \times)$. Diffuse immuno- expression of traditional neuroendocrine markers, Synaptophysin (e, 200x) and Chromogranin A (f, 200x) demonstrated in a case of neuroendocrine breast tumor 
Table 1 Clinico-pathological features of 63 neuroendocrine differentiated breast cancers according to INSM1 expression

\begin{tabular}{|c|c|c|c|c|c|}
\hline Features & & $\begin{array}{l}\text { INSM1 NEGA- } \\
\text { TIVE \#11 }\end{array}$ & INSM1 POSITIVE \#52 & $P$ value & Total (63) \\
\hline Age (years) & Median (interval) & $72(56-93)$ & $75(45-86)$ & 0.545 & $74(45-93)$ \\
\hline \multirow[t]{3}{*}{ Histological grade } & 1 & 4 & 13 & 0.615 & 17 \\
\hline & 2 & 6 & 29 & & 35 \\
\hline & 3 & 1 & 10 & & 11 \\
\hline \multirow[t]{2}{*}{ Vascular invasion } & No & 7 & 28 & 0.553 & 35 \\
\hline & Yes & 4 & 24 & & 28 \\
\hline \multirow[t]{4}{*}{ pT } & 1 & 7 & 31 & 0.824 & 38 \\
\hline & 2 & 4 & 17 & & 21 \\
\hline & 3 & 0 & 2 & & 2 \\
\hline & 4 & 0 & 2 & & 2 \\
\hline \multirow[t]{3}{*}{$\mathrm{pN}$} & 0 & 7 & 38 & 0.340 & 45 \\
\hline & 1 & 4 & 10 & & 14 \\
\hline & 2 & 0 & 4 & & 4 \\
\hline ER & Median (interval) & $95(80-99)$ & $99(10-100)$ & 0.121 & $99(10-100)$ \\
\hline $\operatorname{PgR}$ & Median (interval) & $18(0-98)$ & $80(0-100)$ & 0.702 & $78(0-100)$ \\
\hline \multirow[t]{2}{*}{$\operatorname{PgR}$} & $<20$ & 4 & 11 & 0.282 & 15 \\
\hline & $\geq 20$ & 7 & 41 & & 48 \\
\hline \multirow[t]{3}{*}{ HER2 } & 0 & 10 & 28 & 0.067 & 38 \\
\hline & $1+$ & 1 & 14 & & 15 \\
\hline & $* 2+$ & 0 & 10 & & 10 \\
\hline \multirow[t]{2}{*}{ Surrogate molecular profile } & Luminal A & 4 & 29 & 0.242 & 33 \\
\hline & Luminal B & 7 & 23 & & 30 \\
\hline \multirow[t]{2}{*}{ Ki67 index } & $<20$ & 7 & 30 & 0.716 & 37 \\
\hline & $\geq 20$ & 4 & 22 & & 26 \\
\hline Ki67 index & Median (interval) & $18(4-43)$ & $17(1-80)$ & 0.886 & $18(1-80)$ \\
\hline \multirow[t]{2}{*}{ CGA } & Negative & 5 & 19 & 0.580 & 24 \\
\hline & Focal/diffuse positivity & 6 & 33 & & 39 \\
\hline \multirow[t]{2}{*}{ SYN } & Negative & 0 & 3 & 0.414 & 3 \\
\hline & Focal/diffuse positivity & 11 & 49 & & 60 \\
\hline \multirow[t]{2}{*}{ Surgery } & Conservative & 5 & 31 & 0.389 & 36 \\
\hline & Mastectomy & 6 & 21 & & 27 \\
\hline \multirow[t]{2}{*}{ Recurrences (missing 9) } & No & 9 & 39 & 0.901 & 48 \\
\hline & Yes & 1 & 5 & & 6 \\
\hline \multirow[t]{2}{*}{ Died of disease (missing 3) } & No & 7 & 39 & 0.258 & 46 \\
\hline & Yes & 4 & 10 & & 14 \\
\hline
\end{tabular}

$E R$ estrogen receptor, $P g R$ progesterone receptor, CGA Chromogranin A, SYN Synaptophysin

*All cases that were assessed as 2+ underwent FISH analyses that resulted negative for HER2 gene status

INSM1 was expressed in 28/37 (75.7\%) NET/NEC and 24/26 (92.3\%) other BC with NE features ( $P$ not significant) (Table 2). The intensity and percentage of INSM1 nuclear reactivity were similar in the tumor cell population of NETs and of NECs (Table 3). The extent of biomarker immunoreactivity is summarized in Supplementary Table 2.

Furthermore, no significant clinico-pathological or prognostic differences were detected between INSM1 positive and negative cases in the NET/NEC group (data not shown).

\section{Discussion}

INSM1, a transcription factor expressed during development and maturation of NE cells, has been demonstrated a highly sensitive and specific marker of NE differentiation in pulmonary [24, 25] and gastroenteropancreatic NENs [26, 27]. Its nuclear expression was easily recognizable in small biopsies and cytological specimens with scarce material, contributing to diagnostic accuracy in challenging cases [28, 29]. Although 
Fig. 3 A chart showing INSM1 and Synaptophysin discordant expression in 14/63 cases a and INSM1 and Chromogranin A discordant expression in $25 / 63$ cases $\mathbf{b}$

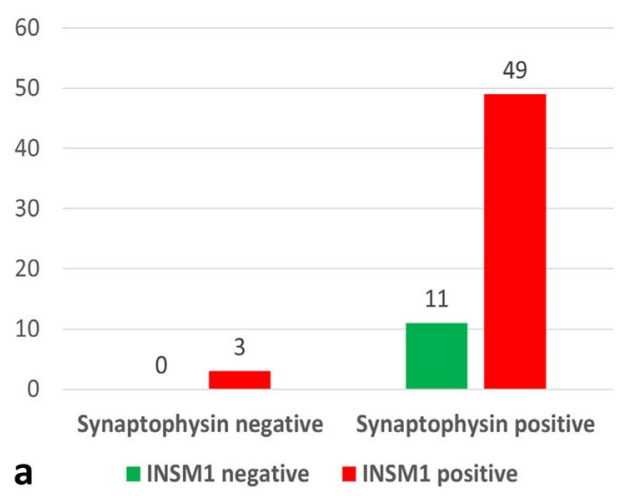

extensively studied, to date, only few papers $[16-18,22]$ reported INSM1 immunoreactivity in BC. The so far reported cases were selected with different criteria, being described as $\mathrm{BC}$ with NE differentiation and, when indicated, they mostly included mucinous, solid papillary, or mixed carcinoma variants, which are not included in the currently proposed WHO categories of breast NEN [3]. In addition, two studies were performed only on tissue microarray cores, which may not allow reliable comparisons among the various series.

In our cases, INSM1 expression was observed in approximately $80 \%$ of BC with NE features, with a high sensitivity and specificity, representing an optimal adjunct in the determination of NE differentiation in BC. However, its expression did not correlate with clinical-pathological characteristics.

In line with other studies, our data demonstrated that INSM1 is more sensitive than CGA but, unlike in other organs, less sensitive than SYN to reveal NE differentiation in BC. Its specificity overlapped that of CGA and SYN [30].

In a previous study from our group [8], another NE marker, the transcription factor hASH1, generally expressed by high-grade NEC of various organs, was investigated in a BC series with NE differentiation (including 17 cases also analyzed in the present study). In the NE cell population, hASH1 expression was found in $63 \%$ and $38 \%$ of cases with an extensive ( $>50 \%)$ or focal $(<50 \%)$ reactivity, respectively. The concordance between hASH1 and INSM1 reactivity was low (41.2\%), as also observed in pulmonary and extrapulmonary NEC. This is probably related to the fact that INSM1 is a target of hASH1 (i.e., ASCL1 gene), but also of the NEUROD1 gene. Thus, in pulmonary and extrapulmonary sites (probably including breast, based on the present findings), INSM1 expression correlates with either one or the other gene, being mutually exclusive and involved in the regulation of different pathways [31-33].

Reviewing all tumors according to the latest WHO edition of BC classification, only $37(58.73 \%)$ cases out of the 63 , originally reported as $\mathrm{BC}$ with $\mathrm{NE}$ differentiation, have been reclassified as NET/NEC. The remaining 26 cases did not meet the novel diagnostic criteria, representing cases of solid-papillary, mucinous, or mixed carcinomas. However, no significant differences were observed in terms of INSM1 expression in the novel NEN categories, compared to the other BC with NE features. Specifically, INSM1 expression was found in $75.7 \%$ of NET/NEC and in $92.3 \%$ of the other histotypes, as expected, being a general marker of NE differentiation.

The latest WHO proposal [3] attempted to make a uniform classification concept, applicable to all human NE tumors, as recommended by a joint International Agency for Research on Cancer (IARC) and WHO group of experts [4]. However, in the BC field, considering that other histotypes may show NE differentiation, traditional NE biomarkers, including INSM1, do not seem to be effective in distinguishing the newly proposed NET/NEC categories of the breast $[3,4]$. In addition, the median expression of INSM1 was similar in NET and NEC cases. These data reinforce its utility in identifying NE differentiation, independently from the intrinsic biological aggressiveness of the NEN subtypes, as described in other organs [25]. In addition, pure breast NENs are probably very rare, being more common the mixed forms, in which an exocrine component co-exists with a NE differentiated cell population. This renders challenging the possibility of perfectly fitting the rigid scheme of NEN classification into NET and NEC, as recently discussed in the review by Uccella and co-workers [34]. In fact, they questioned the attempt to align the classification criteria of NE BC with those of other organs, in the absence of a univocally recognizable morphology and of a clinical behavior different from that of non-NE conventional BC.

The currently described extensive INSM1 expression in $\mathrm{BC}$ with NE differentiation confirms that divergent differentiation driven by known NE-related transcription factors may occur in BC, resulting in a spectrum of tumors, which in part overlap NENs of other organs and in part represent combined/mixed neuroendocrine-exocrine BCs. Further investigations on the significance of $\mathrm{NE}$ features in $\mathrm{BC}$ are warranted. 
Table 2 Clinical pathological features of whole case series according to 2019 WHO classification

\begin{tabular}{|c|c|c|c|c|c|}
\hline & & NET/NEC (37) & $\begin{array}{l}\text { Other NE differenti- } \\
\text { ated BC (26) }\end{array}$ & $P$ value & Total \\
\hline Age (years) & Median (interval) & $73(45-93)$ & $75(46-86)$ & 0.881 & $74(45-85)$ \\
\hline \multirow[t]{3}{*}{ Histological grade } & 1 & 9 & 9 & 0.560 & 17 \\
\hline & 2 & 20 & 15 & & 35 \\
\hline & 3 & 8 & 3 & & 11 \\
\hline \multirow[t]{2}{*}{ Vascular invasion } & No & 20 & 15 & 0.775 & 35 \\
\hline & Yes & 17 & 11 & & 28 \\
\hline \multirow[t]{4}{*}{ pT } & 1 & 24 & 14 & 0.416 & 38 \\
\hline & 2 & 10 & 11 & & 21 \\
\hline & 3 & 1 & 1 & & 2 \\
\hline & 4 & 2 & 0 & & 2 \\
\hline \multirow[t]{3}{*}{ pN } & 0 & 26 & 19 & 0.791 & 45 \\
\hline & 1 & 8 & 6 & & 14 \\
\hline & 2 & 3 & 1 & & 4 \\
\hline ER & Median (interval) & $99(10-100)$ & $95(15-100)$ & 0.452 & $99(10-100)$ \\
\hline $\operatorname{PgR}$ & Median (interval) & $65(0-100)$ & $80(0-99)$ & 0.584 & $60(0-100)$ \\
\hline \multirow[t]{3}{*}{ HER2 } & 0 & 23 & 15 & 0.829 & 38 \\
\hline & $1+$ & 9 & 6 & & 15 \\
\hline & $* 2+$ & 5 & 5 & & 10 \\
\hline \multirow[t]{2}{*}{ Surrogate molecular profile } & Luminal A & 18 & 15 & 0.479 & 33 \\
\hline & Luminal B & 19 & 11 & & 30 \\
\hline \multirow[t]{2}{*}{ Ki67 index } & $<20$ & 21 & 16 & 0.704 & 37 \\
\hline & $\geq 20$ & 16 & 10 & & 26 \\
\hline Ki67 index & Median (interval) & $18(1-80)$ & $16(2-45)$ & 0.740 & $18(1-80)$ \\
\hline \multirow[t]{2}{*}{ CGA } & Negative & 13 & 11 & 0.564 & 24 \\
\hline & Focal/diffuse positivity & 24 & 15 & & 39 \\
\hline \multirow[t]{2}{*}{ SYN } & Negative & 0 & 3 & 0.034 & 3 \\
\hline & Focal/diffuse positivity & 37 & 23 & & 60 \\
\hline \multirow[t]{2}{*}{ INSM1 } & Negative & 9 & 2 & 0.087 & 11 \\
\hline & Positive & 28 & 24 & & 52 \\
\hline \multirow[t]{2}{*}{ Surgery } & Conservative & 18 & 18 & 0.722 & 36 \\
\hline & Mastectomy & 19 & 8 & & 27 \\
\hline \multirow[t]{2}{*}{ Type of therapy (13 missing) } & HT & 25 & 18 & 0.506 & 43 \\
\hline & HT and/or CT & 5 & 2 & & 7 \\
\hline \multirow[t]{2}{*}{ Recurrences (9 missing) } & No & 28 & 20 & 0.236 & 48 \\
\hline & Yes & 5 & 1 & & 6 \\
\hline \multirow[t]{2}{*}{ Died of disease (3 missing) } & No & 25 & 21 & 0.105 & 46 \\
\hline & Yes & 11 & 3 & & 14 \\
\hline
\end{tabular}

$N E$ neuroendocrine, $B C$ breast cancer, $E R$ estrogen receptor, $P g R$ progesterone receptor, $C G A$ Chromogranin A, $S Y N$ Synaptophysin, $H T$ hormonal therapy, $C T$ chemotherapy

*All cases that were assessed as 2+ underwent FISH analyses that resulted negative for HER2 gene status

Table 3 Median percentage distribution of INSM1 in 37 pure NET/ NEC cases, according to WHO 2019

\begin{tabular}{llll}
\hline & $\begin{array}{l}\text { INSM1 positive } \\
\text { cases /total cases }\end{array}$ & $\begin{array}{l}\text { Extent of INSM1 expres- } \\
\text { sion (Median \%) }\end{array}$ & Range \\
\hline NET & $21 / 29(72 \%)$ & 60 & $5-100$ \\
NEC & $7 / 8(78 \%)$ & 70 & $10-100$ \\
\hline
\end{tabular}

In conclusion, our results showed that INSM1 is an accurate NE biomarker that can be employed, together with CGA and SYN, to confirm NE features in BC. However, all these markers recognize a phenotype and not a precise NE entity and cannot be used to distinguish NET/NEC from other breast cancer types with NE differentiation. 
Supplementary Information The online version contains supplementary material available at https://doi.org/10.1007/s12022-021-09682-1.

Author Contribution MP designed the study. JM and EM collected the data and prepared the database. MP, IC, and JM revised the cases. SOA performed the statistical analysis. IC, MP, JM, SOA, and AS interpreted the obtained results. IC, JM, and MP wrote the first draft of the manuscript and all authors critically revised it. All authors read and approved the final version of the manuscript.

Funding Open access funding provided by Università degli Studi di Torino within the CRUI-CARE Agreement.

\section{Declarations}

Ethics Approval The study was approved by the Research Ethics Committee for Human Biospecimen Utilization (Department of Medical Sciences-ChBU) of the University of Turin (no. 5/2020). Written consent was not required considering the retrospective nature of the study. The study was conducted in accordance with The Code of Ethics of the World Medical Association (Declaration of Helsinki). All cases were de-identified, and all clinical-pathological data were accessed anonymously.

Conflict of Interest The authors declare no competing interests.

Open Access This article is licensed under a Creative Commons Attribution 4.0 International License, which permits use, sharing, adaptation, distribution and reproduction in any medium or format, as long as you give appropriate credit to the original author(s) and the source, provide a link to the Creative Commons licence, and indicate if changes were made. The images or other third party material in this article are included in the article's Creative Commons licence, unless indicated otherwise in a credit line to the material. If material is not included in the article's Creative Commons licence and your intended use is not permitted by statutory regulation or exceeds the permitted use, you will need to obtain permission directly from the copyright holder. To view a copy of this licence, visit http://creativecommons.org/licenses/by/4.0/.

\section{References}

1. Tavassoli FA, Devilee P (2003) World Health Organization Classification of Tumours. Pathology and Genetics of Tumours of the Breast and Female Genital Organs, 3rd edn. International Agency for Research on Cancer (IARC) Press, Lyon (France)

2. Lakhani SR, Ellis IO, Schnitt SJ, Tan PH, van de Vijver MJ (2012) WHO Classification of Tumours of the Breast, 4th edn. International Agency for Research on Cancer (IARC) Press, Lyon (France)

3. WHO Classification of Tumours Editorial Board. (2019) Breast tumours, 5th edn. International Agency for Pesearch on Cancer, Lyon (France)

4. Rindi G, Klimstra DS, Abedi-Ardekani B, Asa SL, Bosman FT, Brambilla E, Busam KJ, de Krijger RR, Dietel M, El-Naggar AK, Fernandez-Cuesta L, Klöppel G, McCluggage WG, Moch H, Ohgaki H, Rakha EA, Reed NS, Rous BA, Sasano H, Scarpa A, Scoazec JY, Travis WD, Tallini G, Trouillas J, van Krieken JH, Cree IA (2018) A common classification framework for neuroendocrine neoplasms: an International Agency for Research on Cancer (IARC) and World Health Organization (WHO) expert consensus proposal. Mod Pathol 31:1770-1786. https://doi.org/ 10.1038/s41379-018-0110-y
5. Goto Y, De Silva MG, Toscani A, Prabhakar BS, Notkins AL, Lan MS (1992) A novel human insulinoma-associated cDNA, IA-1, encodes a protein with "zinc-finger" DNA-binding motifs. J Biol Chem 267:15252-15257. https://doi.org/10.1016/S0021-9258(18) 42173-4

6. La Rosa S, Marando A, Gatti G, Rapa I, Volante M, Papotti M, Sessa F, Capella C (2013) Achaete-scute homolog 1 as a marker of poorly differentiated neuroendocrine carcinomas of different sites: A validation study using immunohistochemistry and quantitative real-time polymerase chain reaction on 335 cases. Hum Pathol 44:1391-1399. https://doi.org/10.1016/j.humpath.2012.11.013

7. Bishop JL, Thaper D, Vahid S, Davies A, Ketola K, Kuruma H, Jama R, Nip KM, Angeles A, Johnson F, Wyatt AW, Fazli L, Gleave ME, Lin D, Rubin MA, Collins CC, Wang Y, Beltran H, Zoubeidi A (2017) The master neural transcription factor BRN2 is an androgen receptor-suppressed driver of neuroendocrine differentiation in prostate cancer. Cancer Discov 7:54-71. https://doi. org/10.1158/2159-8290.CD-15-1263

8. Righi L, Rapa I, Votta A, Papotti M, Sapino A (2012) Human achaete-scute homolog-1 expression in neuroendocrine breast carcinoma. Virchows Arch 460:415-421. https://doi.org/10.1007/ s00428-012-1223-1

9. Inamura K (2018) Update on immunohistochemistry for the diagnosis of lung cancer. Cancers (Basel) 10:1-15 . https://doi.org/10. 3390/cancers 10030072

10. Annaratone L, Medico E, Rangel N, Castellano I, Marchiò C, Sapino A, Bussolati G (2014) Search for Neuro-Endocrine Markers (Chromogranin A, Synaptophysin and VGF) in Breast Cancers. An integrated Approach Using Immunohistochemistry and Gene Expression Profiling. Endocr Pathol 25:219-228. https://doi.org/ 10.1007/s12022-013-9277-4

11. Shida T, Furuya M, Kishimoto T, Nikaido T, Tanizawa T, Koda K, Oda K, Takano S, Kimura F, Shimizu H, Yoshidome H, Ohtsuka M, Nakatani Y, Miyazaki M (2008) The expression of NeuroD and $\mathrm{mASH} 1$ in the gastroenteropancreatic neuroendocrine tumors. Mod Pathol 21:1363-1370. https://doi.org/10.1038/modpathol. 2008.121

12. Wildner H, Gierl MS, Strehle M, Pla P, Birchmeier C (2008) Insm1 (IA-1) is a crucial component of the transcriptional network that controls differentiation of the sympatho-adrenal lineage. Development 135:473-481. https://doi.org/10.1242/dev.011783

13. Jia S, Wildner H, Birchmeier C (2015) Insm 1 controls the differentiation of pulmonary neuroendocrine cells by repressing Hes 1 . Dev Biol 408:90-98. https://doi.org/10.1016/j.ydbio.2015.10.009

14. Jia S, Ivanov A, Blasevic D, Müller T, Purfürst B, Sun W, Chen W, Poy MN, Rajewsky N, Birchmeier C (2015) Insm1 cooperates with Neurod 1 and Foxa2 to maintain mature pancreatic $\beta$-cell function. EMBO J 34:1417-1433. https://doi.org/10.15252/embj. 201490819

15. Tanigawa M, Nakayama M, Taira T, Hattori S, Mihara Y, Kondo R, Kusano H, Nakamura K, Abe Y, Ishida Y, Okabe Y, Hisaka T, Okuda K, Fujino K, Ito T, Kawahara A, Naito Y, Yamaguchi R, Akiba J, Akagi Y, Yano H (2018) Insulinoma-associated protein 1 (INSM1) is a useful marker for pancreatic neuroendocrine tumor. Med Mol Morphol 51:32-40. https://doi.org/10.1007/ s00795-017-0167-6

16. Roy M, Buehler DG, Zhang R, Schwalbe ML, Baus RM, Salamat MS, Lloyd R V., Rosenbaum JN (2019) Expression of Insulinoma-Associated Protein 1 (INSM1) and Orthopedia Homeobox (OTP) in Tumors with Neuroendocrine Differentiation at Rare Sites. Endocr Pathol 30:35-42. https://doi.org/10.1007/ s12022-018-9559-y

17. Kawasaki T, Kaira K (2020) Insulinoma-associated protein 1 (INSM1) expression in breast carcinomas with neuroendocrine morphologies: application and future prospective. Virchows Arch. https://doi.org/10.1007/s00428-020-02935-0 
18. Razvi H, Tsang JY, Poon IK, Chan SK, Cheung SY, Shea KH, Tse GM (2021) INSM1 is a novel prognostic neuroendocrine marker for luminal B breast cancer. Pathology 53:170-178. https://doi. org/10.1016/j.pathol.2020.07.004

19. Goldhirsch A, Wood WC, Coates AS, Gelber RD, Thürlimann B, Senn HJ (2011) Strategies for subtypes-dealing with the diversity of breast cancer: Highlights of the St Gallen international expert consensus on the primary therapy of early breast cancer 2011. Ann Oncol 22:1736-1747. https://doi.org/10.1093/annonc/ mdr304

20. Wolff AC, Hammond MEH, Allison KH, Harvey BE, Mangu PB, Bartlett JMS, Bilous M, Ellis IO, Fitzgibbons P, Hanna W, Jenkins RB, Press MF, Spears PA, Vance GH, Viale G, McShane LM, Dowsett M (2018) Human Epidermal Growth Factor Receptor 2 Testing in Breast Cancer: American Society of Clinical Oncology/College of American Pathologists Clinical Practice Guideline Focused Update. J Clin Oncol Off J Am Soc Clin Oncol 36:21052122. https://doi.org/10.1200/JCO.2018.77.8738

21. Goldhirsch A, Winer EP, Coates AS, Gelber RD, Piccart-Gebhart M, Thürlimann B, Senn H-J (2013) Personalizing the treatment of women with early breast cancer: highlights of the St Gallen International Expert Consensus on the Primary Therapy of Early Breast Cancer 2013. Ann Oncol Off J Eur Soc Med Oncol 24:2206-2223. https://doi.org/10.1093/annonc/mdt303

22. Seijnhaeve E, Galant C, Van Bockstal MR (2021) Nuclear Insulinoma-Associated Protein 1 Expression as a Marker of Neuroendocrine Differentiation in Neoplasms of the Breast. Int J Surg Pathol 9:1066896920985938. https://doi.org/10.1177/1066896920985938

23. Simon R (2015) Sensitivity, Specificity, PPV, and NPV for Predictive Biomarkers. J Natl Cancer Inst 107:24-26. https://doi.org/10. 1093/jnci/djv153

24. Kriegsmann K, Zgorzelski C, Kazdal D, Cremer M, Muley T, Winter H, Longuespée R, Kriegsmann J, Warth A, Kriegsmann M (2020) Insulinoma-associated Protein 1 (INSM1) in thoracic tumors is less sensitive but more specific compared with synaptophysin, Chromogranin A, and CD56. Appl Immunohistochem Mol Morphol 28:237-242. https://doi.org/10.1097/PAI.0000000000000715

25. Mukhopadhyay S, Dermawan JK, Lanigan CP, Farver CF (2019) Insulinoma-associated protein 1 (INSM1) is a sensitive and highly specific marker of neuroendocrine differentiation in primary lung neoplasms: an immunohistochemical study of 345 cases, including 292 whole-tissue sections. Mod Pathol 32:100-109. https:// doi.org/10.1038/s41379-018-0122-7

26. McHugh KE, Mukhopadhyay S, Doxtader EE, Lanigan C, Allende DS (2020) INSM1 Is a Highly Specific Marker of Neuroendocrine
Differentiation in Primary Neoplasms of the Gastrointestinal Tract, Appendix, and Pancreas. Am J Clin Pathol 153:811-820. https://doi.org/10.1093/ajcp/aqaa014

27. González I, Lu HC, Sninsky J, Yang C, Bishnupuri K, Dieckgraefe B, Cao D, Chatterjee D (2019) Insulinoma-associated protein 1 expression in primary and metastatic neuroendocrine neoplasms of the gastrointestinal and pancreaticobiliary tracts. Histopathology 75:568-577. https:// doi.org/10.1111/his.13899

28. Takase Y, Naito Y, Okabe Y, Ishida Y, Yamaguchi T, Abe H, Murata K, Ito T, Tanigawa M, Kawahara A, Yano H, Akiba J (2019) Insulinoma-associated protein 1 expression in pancreatic neuroendocrine tumours in endoscopic ultrasound-guided fineneedle aspiration cytology: An analysis of 14 patients. Cytopathology 30:194-200. https://doi.org/10.1111/cyt.12640

29. Viswanathan K, Siddiqui MT, Borczuk AC (2019) Insulinomaassociated protein 1 is a sensitive and specific marker for lung neuroendocrine tumors in cytologic and surgical specimens. J Am Soc Cytopathol 8:299-308. https://doi.org/10.1016/j.jasc.2019.06. 002

30. Rooper LM, Sharma R, Li QK, Illei PB, Westra WH (2017) INSM1 Demonstrates Superior Performance to the Individual and Combined Use of Synaptophysin, Chromogranin and CD56 for Diagnosing Neuroendocrine Tumors of the Thoracic Cavity. Am J Surg Pathol 41:1561-1569. https://doi.org/10.1097/PAS. 0000000000000916

31. Yatabe Y (2020) Reassessing the SCLC Subtypes. J Thorac Oncol 15:1819-1822. https://doi.org/10.1016/j.jtho.2020.10.011

32. Mahalakshmi B, Baskaran R, Shanmugavadivu M, Nguyen NT, Velmurugan BK (2020) Insulinoma-associated protein 1 (INSM1): a potential biomarker and therapeutic target for neuroendocrine tumors. Cell Oncol 43:367-376. https://doi.org/10. 1007/s13402-020-00505-9

33. Borromeo MD, Savage TK, Kollipara RK, He M, Augustyn A, Osborne JK, Girard L, Minna JD, Gazdar AF, Cobb MH JJ (2016) ASCL1 and NEUROD1 reveal heterogeneity in pulmonary neuroendocrine tumors and regulate distinct genetic programs. Cell Rep 16:1259-1272. https://doi.org/10.1016/j.celrep.2016.06.081

34. Uccella S, Finzi G, Sessa F, La Rosa S (2020) On the Endless Dilemma of Neuroendocrine Neoplasms of the Breast: a Journey Through Concepts and Entities. Endocr Pathol 31:321-329. https://doi.org/10.1007/s12022-020-09637-y

Publisher's Note Springer Nature remains neutral with regard to jurisdictional claims in published maps and institutional affiliations. 